\title{
Serum Profile of Lactate Dehydrogenase (LDH) and Alkaline Phosphatase (ALP) in Alcoholic Liver Diseases
}

\section{Agnieszka Grytczuk}

4 Wojskowy Szpital Kliniczny z Poliklinika SP ZOZ we Wroclawiu

\section{Ewa Gruszewska}

Uniwersytet Medyczny w Bialymstoku

Anatol Panasiuk

Uniwersytet Medyczny w Bialymstoku

\section{Bogdan Cylwik}

Uniwersytet Medyczny w Bialymstoku

Lech Chrostek ( $\nabla$ chrostek@umb.edu.pl)

Uniwersytet Medyczny w Bialymstoku

\section{Research}

Keywords: Lactate dehydrogenase, Alkaline phophatase, Isoenzymes, Alcoholic liver diseases

Posted Date: June 26th, 2020

DOl: https://doi.org/10.21203/rs.3.rs-36175/v1

License: (c) (i) This work is licensed under a Creative Commons Attribution 4.0 International License. Read Full License 
Serum profile of Lactate Dehydrogenase (LDH) and Alkaline Phosphatase (ALP) in alcoholic liver diseases

Agnieszka Grytczuk ${ }^{1}$, Ewa Gruszewska ${ }^{2}$, Anatol Panasiuk ${ }^{3}$, Bogdan Cylwik $^{4}$ and Lech Chrostek $^{* 2}$

${ }^{1}$ Department of Laboratory Diagnostics, University Clinical Hospital in Bialystok, Bialystok, Poland

${ }^{2}$ Department of Biochemical Diagnostics, Medical University of Bialystok, Bialystok, Poland

${ }^{3}$ Department of Internal Diseases and Gastroenterology, Provincial Welded Hospital in Bialystok, Bialystok, Poland

${ }^{4}$ Department of Pediatric Laboratory Diagnostics, Medical University of Bialystok, Bialystok, Poland

Running head: Serum LDH and ALP in alcoholic liver diseases

Corresponding author: Prof. Lech Chrostek, Department of Biochemical Diagnostics, Medical University of Bialystok, Waszyngtona 15A, 15-269 Bialystok, Poland, Tel./Fax: +48 8583185 85; E-mail: chrostek@umb.edu.pl 


\section{Abstract}

Background: Alcohol-related liver diseases affect the capability of the liver for the synthesis of proteins including enzymes. Among enzymes two expose the liver specific isoenzymes. There are lactate dehydrogenase and alkaline phosphatase. The purpose of this study was to explore the profile of lactate dehydrogenase and alkaline phosphatase isoenzymes in alcoholic liver diseases.

Methods: The serum profile of lactate dehydrogenase and alkaline phosphatase isoenzymes was studied in alcoholic cirrhosis and alcoholic hepatitis by electrophoresis method on agarose gel.

Results: The relative concentration of LDH 1 isoenzyme is decreased in alcoholic hepatitis, but LDH 4 and LDH 5 isoenzymes are increased. In addition, the relative level of LDH 5 isoenzyme is increased in alcoholic cirrhosis. The concentrations of intermediate isoenzymes (LDH 2 and LDH 3) are reduced in alcoholic cirrhosis. There were also an increase of liver ALP isoenzyme and parallel decrease in its bone isoenzyme in alcoholic hepatitis and cirrhosis. The severity of liver cirrhosis, expressed as a Child-Pugh score, didn't affect total activity of both enzymes but effects the relative concentration of LDH 2, LDH 3 and LDH 4 isoenzymes.

Conclusions: The serum profile of lactate dehydrogenase and alkaline phosphatase isoenzymes alters in alcoholic liver diseases and differs between them. The differences can be explained by the tissue prevalence and metabolic preferences of isoenzymes.

Key words: Lactate dehydrogenase, Alkaline phophatase, Isoenzymes, Alcoholic liver diseases 


\section{Introduction}

Lactate dehydrogenase (LDH) and alkaline phosphatase (ALP) are enzymes present in all human tissues with the greatest amount in the liver. There are known multiple variations of LDH and ALP called isoenzymes, each of them with a different structure. The isoenzymes are found in various tissues and normal serum isoenzymes profile is the result of normal tissue breakdown. These distinct isoenzymes are released from damaged or diseased tissue into the blood and the origin of isoenzymes can be established in the laboratory $[1,2]$.

There are five different LDH isoenzymes that can be detected in serum by electrophoresis according to their electrophoretic mobilities from anode to cathode as LDH 1, LDH 2, LDH 3 , LDH 4, and LDH 5 [3]. LDH-1 isoenzyme is primarily present in cardiac myocytes and erythrocytes, LDH-2 mostly present in white blood cells, LDH-3 in highest quantity in lung tissue, LDH-4 in highest amounts found in pancreas, kidney, and placenta and LDH-5 isoenzyme in highest amounts is found in liver and skeletal muscle._f an organ is damaged, its LDH isoenzymes will be proportionally increased in the blood stream. Today, clinical utility of LDH has been relegated to confirm hemolysis and serve as a tumor marker [4]. But we wolud to try to test the ability of LDH isoenzymes determination to explain the role of LDH in alcoholic liver diseases. $\mathrm{LDH}$ is an enzyme involved in the metabolism of glucose which is deranged in long lasting alcohol drinking [5,6].

Essentially, four main ALP isoenzymes, each with a different structure, are found in different tissues: bone, liver, intestinal and placental [7]. Liver ALP isoenzyme is most frequently elevated when total ALP level is elevated. The liver ALP increases in the blood before most other liver dysfunction tests point to abnormalities. Generally, alkaline phosphatase is an important serum analyte and its elevation in serum is correlated with the presence of bone, liver, and other diseases [8]. The conditions leading to increased liver ALP include an acute 
hepatitis, cirrhosis, fatty liver, drug induced liver disease, obstruction of biliary flow by carcinoma at the head of pancreas, bile duct stricture, primary biliary cirrhosis and metastatic carcinoma of the liver [9]. The aim of this work was to determine and compare the profile of LDH and ALP isoenzymes in alcoholic liver diseases. Liver biopsy - the gold standard to evaluate fibrosis and fatty liver diseases, is not recomended and not widely accepted (recommended) as the reference standard in alcoholic liver disease [10]. Therefore, we would like to look for noninvasive tools for diagnosis and differentiatie alcoholic liver diseases alcoholic cirrhosis and alcoholic hepatitis.

\section{Material and methods}

\section{Subjects}

The tested group consisted of 80 patients with alcoholic liver diseases, including 55 patients with alcoholic cirrhosis (41 men, age range: 29 - 76, mean: 55) and 25 patients with alcoholic hepatitis (19 men, age range: 24 - 76, mean: 46) admitted to the Department of Infectious Diseases and Hepatology (University Clinical Hospital in Bialystok). The diagnosis of liver diseases was based on the clinical data (signs, symptoms, physical exams, biochemical liver panel (PLT, MCV, INR, AST, ALT, GGT, albumin and bilirubin), abdominal ultrasound,or computed tomagraphy (CT) scan of the abdomen. The diagnosis of toxic hepatitis included medical history, symptoms, liver function laboratory tests (AST, ALT, bilirubin), abdominal ultrasound, CT or MRI. All patients were interviewed regarding their use of alcohol. Characteristic of tested group is presented in Table 1.

The control group consisted of 30 healthy subjects (13 female, 17 males, age range: 21 - 54) without history of alcohol abuse. Informed consent was obtained from all individuals (healthy and sick). The study was performed in accordance with Helsinki Declaration and was approved by the Bioethical Committee at Medical University of Bialystok. 


\section{Sample collection}

Blood samples from patients were collected by peripheral vein puncture into tubes without anticoagulants. The serum samples were separeted by centrifugation at $1500 \mathrm{xg}$ for $10 \mathrm{~min}$ at room temperature and stored at $-86^{\circ} \mathrm{C}$ until analysed. Besides serum, a part of each blood sample was collected into tubes containing EDTA-2 for hematological analyses and 3.8\% liquid sodium citrate for haemostatis analysis.

\section{Isoforms separation}

The LDH and ALP isoenzymes are separated on agarose gel according to their isoelectrical point in alkaline buffer. After electrophoresis, the isoenzymes are revealed by incubation with a specific enzymatic reaction. The system calculates relative concentration (\%) of each fraction automatically. Normal values for LDH isoenzymes are lacated within limits; LDH 1 from 20 to $30 \%$, LDH 2 from 30 to $40 \%$, LDH 3 from 20 to $25 \%$, LDH 4 from 7 to $15 \%$ and LDH 5 from 5 to $15 \%$. The sensitivity study showed that the system is detected up to 3U/L. The system has been validated to be linear between 1250 and 156 total LDH activity. Reference values for normal levels of ALP isoenzymes were established as follow: liver ALP: 40-60\%, bone: $30-70 \%$ and intestinal $<10 \%$. The lowest detected activity of the liver and bone ALP isoenzyme by densitometry was respectively, 1.7UI/L and 3UI/L.

\section{Determination of other tests}

AST, ALT, GGT, albumin and bilirubin were determined on the Architect c8000 (Abbott Laboratories, Abbott Park, USA). MCV and PLT count was measured on Sysmex XS-800i (Sysmex Corporation, Singapure). PT was measured on STA Compact Max analyzer (Stago) by viscometric method. 


\section{Statistical analysis}

Results were expressed as means and standard deviations. The differences between tested and control groups were evaluated by Mann-Whitney U-test. The ANOVA rank Kruskal-Wallis test was performed to analyze data according to grading and staging of cirrhosis. We considered $\mathrm{P}$ values $<0.05$ as statistically significant.

\section{Results}

The mean serum total LDH and ALP activity were significantly higher in patients with alcoholic cirrhosis and alcoholic hepatitis when compared to the controls $(\mathrm{P}<0.001$ for both comparisons). The changes in serum LDH and ALP isoenzymes distribution are presented in Figure 1 and 2. The relative concentrations of LDH 2 and LDH3 isoenzymes in alcoholic cirrhosis were significantly lower but LDH 5 isoenzyme, significantly higher, in comparison with the control group $(\mathrm{P}=0.030 ; \mathrm{P}=0.048$ and $\mathrm{P}=0.009$, respectively) (Fig. 1). Liver ALP isoenzyme level was higher $(\mathrm{P}=0.020)$ and bone ALP isoenzyme was lower in cirrhosis when compared to the healthy group (Fig. 2). The ratio of LDH4/LDH5 significantly diminished in alcoholic cirrhosis $(\mathrm{P}=0.007)$. The relative concentrations of LDH 1 isoenzyme in alcoholic hepatitis was lower than that in the control group $(\mathrm{P}=0.015)$, but LDH 4 and LDH 5 isoenzymes were significantly higher $(\mathrm{P}=0.001$ and $\mathrm{P}=0.029$, respectively) (Fig. 1). The concentration of liver ALP isoenzyme was higher $(\mathrm{P}<0.001)$ but bone ALP isoenzyme significantly lower $(\mathrm{P}<0.001)$ when compared to the control group (Fig. 2). In this group of patients the ratio of $\mathrm{LDH} 4 / \mathrm{LDH} 5$ was unchanged $(\mathrm{P}=0.841)$.

When compared alcoholic cirrhosis to hepatitis, there were significantly higher relative level of $\mathrm{LDH} 4$ isoenzyme and liver ALP isoenzyme in hepatitis than that in cirrhosis $(\mathrm{P}=0.009$ and $\mathrm{P}<0.001)$, but lower level of bone ALP isoenzyme in toxic hepatitis $(\mathrm{P}=0.001)$. The ratio of LDH 4/LDH 5 did not significantly differ between these groups of patients. 
ANOVA rank Kruskal-Wallis analysis showed that severity of liver cirrhosis, expressed as a Child-Pugh score, effects the relative concentration of LDH 2, LDH 3 and LDH 4 isoenzymes ( $\mathrm{P}=0.022, \mathrm{P}=0.007, \mathrm{P}=0.021$, respectively) (Fig. 3). The relative concentrations of LDH 2 isoenzyme was higher in class $\mathrm{C}$ in comparison with class $\mathrm{A}(\mathrm{P}=0.029)$ and the relative concentration of LDH 3 was lower in class $\mathrm{C}$ than that in class $\mathrm{A}(\mathrm{P}=0.007)$. The level of LDH 4 isoenzyme in class $\mathrm{C}$ was lower than in class $\mathrm{B}(\mathrm{P}=0.034)$. The severity of liver cirrhosis didn't affect the activity of liver and bone ALP ( $\mathrm{P}=0.078$ for liver and $\mathrm{P}=0.130$ for bone isoenzyme) (Fig. 4). Also, the severity of alcoholic liver cirrhosis didn't affect total activity of both enzymes $(\mathrm{P}=0.422$ for total activity of $\mathrm{LDH}$ and $\mathrm{P}=0.450$ for total activity of ALP).

\section{Discussion}

Let's go over the main points of our work. Firstly, the relative concentration of LDH 1 isoenzyme present primarily in cardiac myocytes and erythrocytes, is decreased in alcoholic hepatitis, but LDH 4 and LDH 5 isoenzymes which are found in highest amounts in the liver and skeletal muscles, are increased in alcoholic hepatitis. Additionally, the relative level of LDH 5 isoenzyme is also increased in alcoholic cirrhosis. The concentrations of isoenzymes containing intermediate amounts of $\mathrm{H}$ subunits (LDH 2 and LDH 3) are reduced in alcoholic cirrhosis. The changes in LDH profile in alcoholic liver diseases can be explained by differences in $\mathrm{Km}$ pyruvate and $\mathrm{Km}$ lactate for isoenzymes and by tissue prevalence of isoenzymes. Thus, isoenzymes containing large proportions of $\mathrm{H}$ subunits (LDH 1 and LDH2) tend to predominate in tissues with aerobic metabolism (e.g. heart) but isoenzymes containing mostly M subunits (LDH 4 and LDH 5) are found in tissues with considerable anaerobic metabolism (e.g. liver and skeletal muscle) [4]. The high concentrations of pyruvate are optimal for isoenzymes rich in M subunits (it means for LDH 4 and LDH 5) but cause inhibition of isoenzymes rich in H subunits (LDH 1 and LDH 2) [11]. The LDH enzyme 
catalyzes the reversible transformation of pyruvate to lactate under anaerobic conditions therefore plays a key role in regulating glycolysis by catalyzing the final step of anaerobic glycolysis. The subsequent fate of the pyruvate depends on the oxygen conditions in the cell. When oxygen levels in cells are low, pyruvate is converted to lactate, which can accumulate and the largest proportion of ATP is produced during glycolysis [12]. If enough oxygen is present, pyruvate is transported into mitochondria in which enters a chain of biochemical reactions collectively called the citric acid cycle, degrading pyruvate to carbon dioxide. It is well known that alcohol directly enhances the liver's oxygen use through its own breakdown in the hepatocytes. In these conditions pyruvate is subsequently converted to lactate, which also accumulate in the liver cells [5,6]. One reason why glycolysis is reduced in chronic alcohol users could be that the cells do not contain enough of glucose, primary source of ATP production. Glucose can either enter into hepatocyte from the blood by specific transport molecules located in the hepatocyte membrane, or it can be generated inside the hepatocyte from glycogen, which is a storage form of glucose in liver cells. Accordingly, reduced glycolysis could be related to lowered cellular glucose uptake and/or glycogen breakdown [13]. Our results can be explained by the fact that isoenzyrnes rich in $\mathrm{H}$ units (LDH 1 isoenzyme) are inhibited by high pyruvate concentration in the liver and blood in chronic alcohol abusers, while isoenzymes rich in M units (LDH 4 and LDH 5 isoenzymes) show optimal activity with high pyruvate. However, the main cause of increased levels of LDH 4 and LDH 5 isoenzymes is response to tissue injury, necrosis and hypoxia in the livers of alcohol users $[14,15]$.

There was not a surprise that liver failure during excessive alcohol drinking loads to increase of liver ALP isoenzyme and parallel decrease in bone isoenzyme. The changes in alcoholic hepatitis are more expressed than the changes in alcoholic cirrhosis since the long-term liver damage in the course of cirrhosis exhausts the ability of that organ to synthesis of proteins, 
including enzymes. That regularity can be also visible in the behaviour of other liver proteins such as alanine and aspartate aminotransferase, $\gamma$-glutamyl transferase and albumin. The serum activity of enzymes and an albumin concentration were lower (but significantly elevated in comparison to the control group) in alcoholic cirrhosis than that in alcoholic hepatitis. In the alcoholic hepatitis, typical biochemical changes include elevated AST (up to 2 to 6 times the upper limit of normal) and elevated ALT to a lesser extent, with an AST-toALT ratio greater than 2 [16]. Neutrophilia, anemia, hyperbilirubinemia, and coagulopathy with an elevated international normalized ratio are common [17]. The clinical picture of alcoholic hepatitis is also characterized by jaundice [18]. If so, we expect to get an elevated blood concentration of bilirubin and ALP activity. The serum bilirubin concentration in AC and AH was elevated but didn't differ between groups such as AST, ALT, GGT, albumin and PT. Alkaline phosphatase is located on the exterior surface of the bile canalicular portion of the plasma membrane. In patients with obstructive jaundice the appearance of fast liver or a-1 liver high-molecular weight alkaline phosphatase band on electrophoresis was described [9]. Surprisingly, in patients with cirrhosis, particularly in subjects with blood group $\mathrm{O}$, the appearance of electrophoretic bands of intestinal alkaline phosphatase was demostrated [9].

\section{Conclusion}

The serum profile of lactate dehydrogenase and alkaline phosphatase isoenzymes in alcoholic cirrhosis and hepatitis differs between diseases. It is obvious that increased level of liver isoenzymes was accompanied by decreased level of isoenzymes originating from other organs. Some LDH isoenzymes may reflect the severity of alcoholic liver cirrhosis. 


\section{Abbreviations}

AC: Alcoholic cirrhosis; AH: Alcoholic hepatitis; ALP: Alcaline phosphatase; ALT: Alanine aminotransferase; AST: Aspartate aminotransferase; ATP: Adenosine triphosphate; EDTA: Ethylenediamine-tetra-acetic-acid; GGT: $\gamma$-glutamyltransferase; INR: Iinternational normalized ratio; Km: Michaelis-Menten constant; LDH: Lactate dyhydrogenase; MCV: Mean corpuscular volume; PLT: Platelet count; PT: Prothrombin time

\section{References}

1. Pincus MR, Abraham NZ, Carty RP. Henry's Clinical Diagnosis and Management by Laboratory Methods. In: McPherson RA, Pincus MR, eds. Clinical Enzymology, 22nd edn. Philadelphia: Elsevier Saunders, 2011; 273-95.

2. Panteginini M, Bais R. Serum enzymes. In: Burtis C, Bruns D, eds. Teitz Fundamentals of Clinical Chemistry and Molecular Diagnostics, 7th edn. St Louis: Elsevier Saunders, 2014; 318-36.

3. Lott JA, Nemesanszky E. Lactate dehydrogenase (LD). In: Lott JA, Wolf PL, eds. Clinical enzymology. A case-oriented approach, New York: Field and Richl Year Book, $1986 ; 213-44$.

4. Jialal I, Sokoll LJ. Clinical utility of lactate dehydrogenase: a historical perspective. Am J Clin Pathol 2015; 143: 158-9.

5. Baio DL, Czyz CN, Van Horn CG, Ivester P, Cunningham CC. Effect of chronic ethanol consumption on respiratory and glycolytic activities of rat periportal and perivenous hepatocytes. Arch Biochem Biophys 1998; 350: 193-200.

6. Van Horn CG, Cunningham CC. Contributions of dietary carbohydrate and ethanol to alterations in liver glycogen levels and glycolytic activity. Alcohol 1999; 19: 139-44. 
7. Sharma U, Pal D, Prasad R. Alkaline Phosphatase: An Overview. Indian J Clin Biochem 2014; 29: 269-78.

8. Epstein E, Kiechle FL, Artiss JD, Zak, B. The clinical use of alkaline phosphatase enzymes. Clin Lab Med 1986; 6: 491-505.

9. Narayanan S. Serum Alkaline Phosphatase Isoenzymes as Markers of Liver Disease. Ann Clin Lab Sci 1991; 21: 12-8.

10. Kobyliak N, Dynnyk O, Abenavoli L. The Role of Liver Biopsy to Assess Alcoholic Liver Disease. Rev Recent Clin Trials 2016; 11: 175-9.

11. Goodfriend TL, Kaplan NO. Isoenzymes in clinical diagnosis. Circulation 1965; 32: 1010-19.

12. Berg JM, Tymoczko JL, Stryer L. Biochemistry. 2002, 5th edn. New York: WH Freeman.

13. Van Horn CG, Ivester P, Cunningham CC. Chronic ethanol consumption and liver glycogen synthesis. Arch Biochem Biophys 2001; 392: 145-52.

14. Ishak KG, Zimmerman HJ, Ray MB. Alcoholic liver disease: Pathologic, pathogenetic and clinical aspects. Alcoholism: Clin Exp Res 1991; 15: 45-66.

15. Arteel, GE, Raleigh, J, Bradford BU, Thurman, RG. Acute alcohol produces hypoxia directly in rat liver tissue in vivo: Role of Kupffer cells. Am J Physiol 1996; 271: G494G500.

16. Cohen JA, Kaplan MM. The SGOT/SGPT ratio_-an indicator of alcoholic liver disease. Dig Dis Sci 1979; 24: 835-8.

17. Dugum M, Zein N, McCullough A, Hanouneh I. Alcoholic hepatitis: Challenges in diagnosis and management. Clev Clin J Med 2015; 4: 226-36.

18. Singal AK, Bataller R, Ahn J, Kamath PS, Shah VH. ACG Clinical Guideline: Alcoholic Liver Disease. Am J Gastroenterol 2018; 113: 175-94. 


\section{Acknowledgements}

Not applicable.

\section{Authors'contributions}

AG and EG performed the experiments. AG and LC designed the research study. All authors analyzed and interpreted the data. AP managed and processed clinical data. AG and EG wrote the paper. BC and LC critically reviewed the manuscript for intellectual content. All authors read and approved the final manuscript.

\section{Funding}

Study was supported by the Polish Ministry of Science and Higher Education.

\section{Availability of data and materials}

The datasets generated and analyzed during the study are available from the corresponding author on reasonable request.

\section{Ethics approval and consent to participate}

This study was approved by Bioethical Committee (BC) of Medical University in Bialystok.

\section{Consent for publication}

All authors approved the manuscript and gave their consent for publication.

\section{Competing interests}

The authors declare that they have no competing interests. 


\section{Author details}

${ }^{1}$ Department of Laboratory Diagnostics, University Clinical Hospital in Bialystok, Bialystok, Poland

${ }^{2}$ Department of Biochemical Diagnostics, Medical University of Bialystok, Bialystok, Poland

${ }^{3}$ Department of Internal Diseases and Gastroenterology, Provincial Welded Hospital in Bialystok, Bialystok, Poland

${ }^{4}$ Department of Pediatric Laboratory Diagnostics, Medical University of Bialystok, Bialystok, Poland

\section{Corresponding author}

Correspondence to Lech Chrostek 
Table 1 Characteristics of tested patients and control group

\begin{tabular}{|l|c|c|c|c|c|c|c|c|}
\hline & $\begin{array}{c}\text { MCV } \\
(\mathrm{fl})\end{array}$ & $\begin{array}{c}\text { PLT } \\
\left(\mathrm{x} 10^{3} / \mu \mathrm{l}\right)\end{array}$ & $\begin{array}{c}\text { PT } \\
(\mathrm{sek})\end{array}$ & $\begin{array}{c}\text { AST } \\
(\mathrm{IU} / \mathrm{l})\end{array}$ & $\begin{array}{c}\text { ALT } \\
(\mathrm{IU} / \mathrm{l})\end{array}$ & $\begin{array}{c}\text { GGT } \\
(\mathrm{IU} / \mathrm{l})\end{array}$ & $\begin{array}{c}\text { Albumin } \\
(\mathrm{g} / \mathrm{dl})\end{array}$ & $\begin{array}{c}\text { Bilirubin } \\
(\mu \mathrm{M} / \mathrm{l})\end{array}$ \\
\hline Controls & $87 \pm 4.5$ & $235 \pm 51$ & $12.4 \pm 0.4$ & $23 \pm 5$ & $17 \pm 8$ & $23 \pm 7$ & $4 \pm 0.6$ & $12.3 \pm 5.3$ \\
\hline \multirow{2}{*}{$\mathrm{AC}$} & $\begin{array}{c}97 \pm 8.9 \\
*\end{array}$ & $\begin{array}{c}128 \pm 104 \\
*\end{array}$ & $\begin{array}{c}17.4 \pm 7.8 \\
*\end{array}$ & $\begin{array}{c}104 \pm 111 \\
*\end{array}$ & $\begin{array}{c}44 \pm 47 \\
*\end{array}$ & $\begin{array}{c}392 \pm 499 \\
*\end{array}$ & $\begin{array}{c}3 \pm 0.6 \\
*\end{array}$ & $\begin{array}{c}114 \pm 131 \\
*\end{array}$ \\
\hline \multirow{2}{*}{$\mathrm{AH}$} & $96 \pm 6.7$ & $\begin{array}{c}195 \pm 92 \\
*\end{array}$ & $\begin{array}{c}16 \pm 16.3 \\
\#\end{array}$ & $\begin{array}{c}158 \pm 127 \\
* \#\end{array}$ & $\begin{array}{c}177 \pm 176 \\
* \#\end{array}$ & $\begin{array}{c}1001 \pm 1000 \\
* \#\end{array}$ & $\begin{array}{c}3.6 \pm 0.6 \\
* \#\end{array}$ & $\begin{array}{c}98 \pm 132 \\
*\end{array}$ \\
\hline
\end{tabular}

Data are means \pm SD. * significant difference in comparison to the control group. \#significant difference in comparison between alcoholic cirrhosis (AC) and alcoholic hepatitis (AH). 


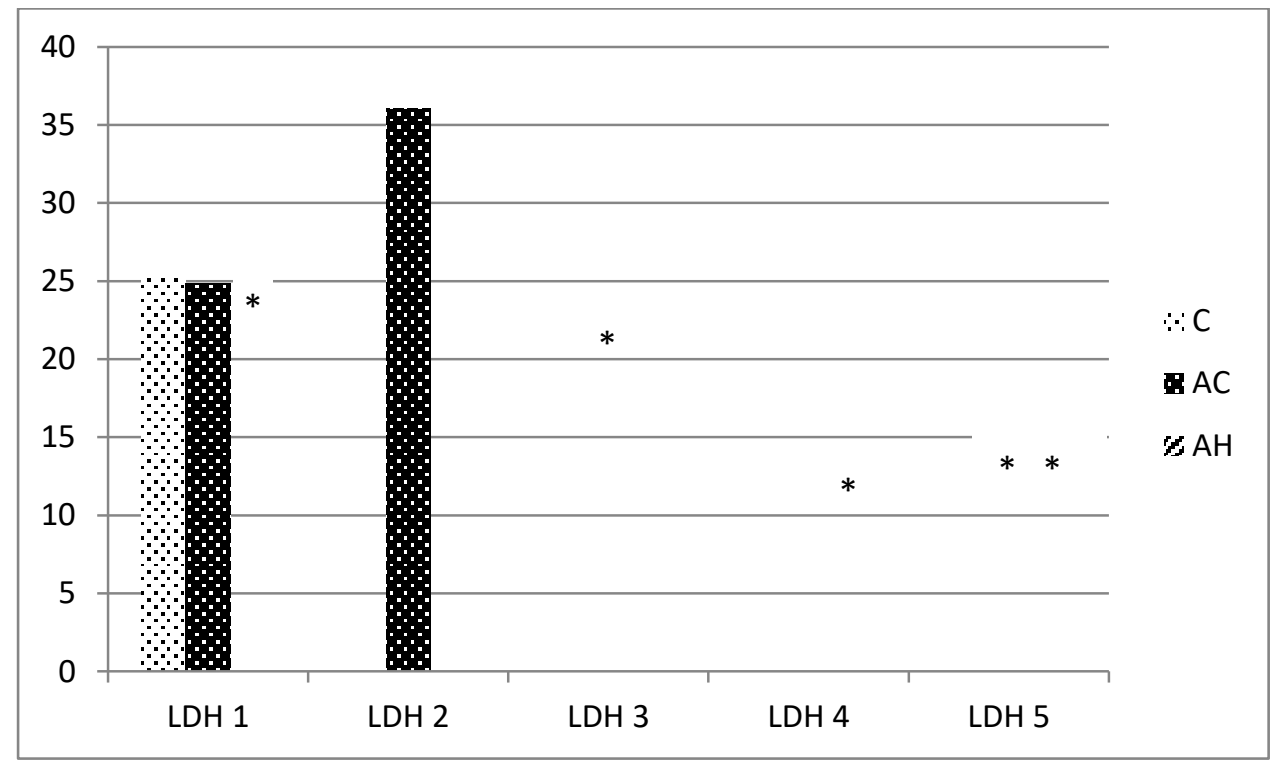

Fig. 1 The relative concentrations of LDH isoenzymes in alcoholic hepatitis (AH), alcoholic cirrhosis (AC) and in the control group (C) 


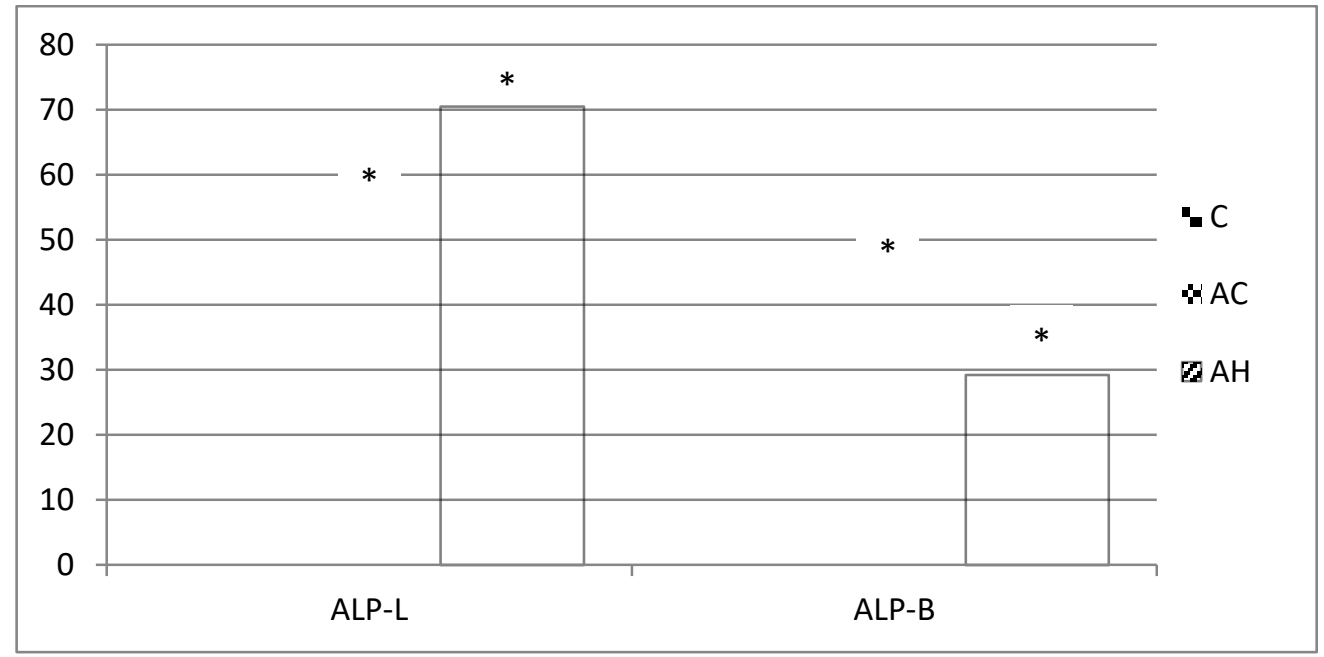

Fig. 2 The relative concentrations of ALP isoenzymes in alcoholic hepatitis (AH), alcoholic cirrhosis (AC) and in the control group (C) 

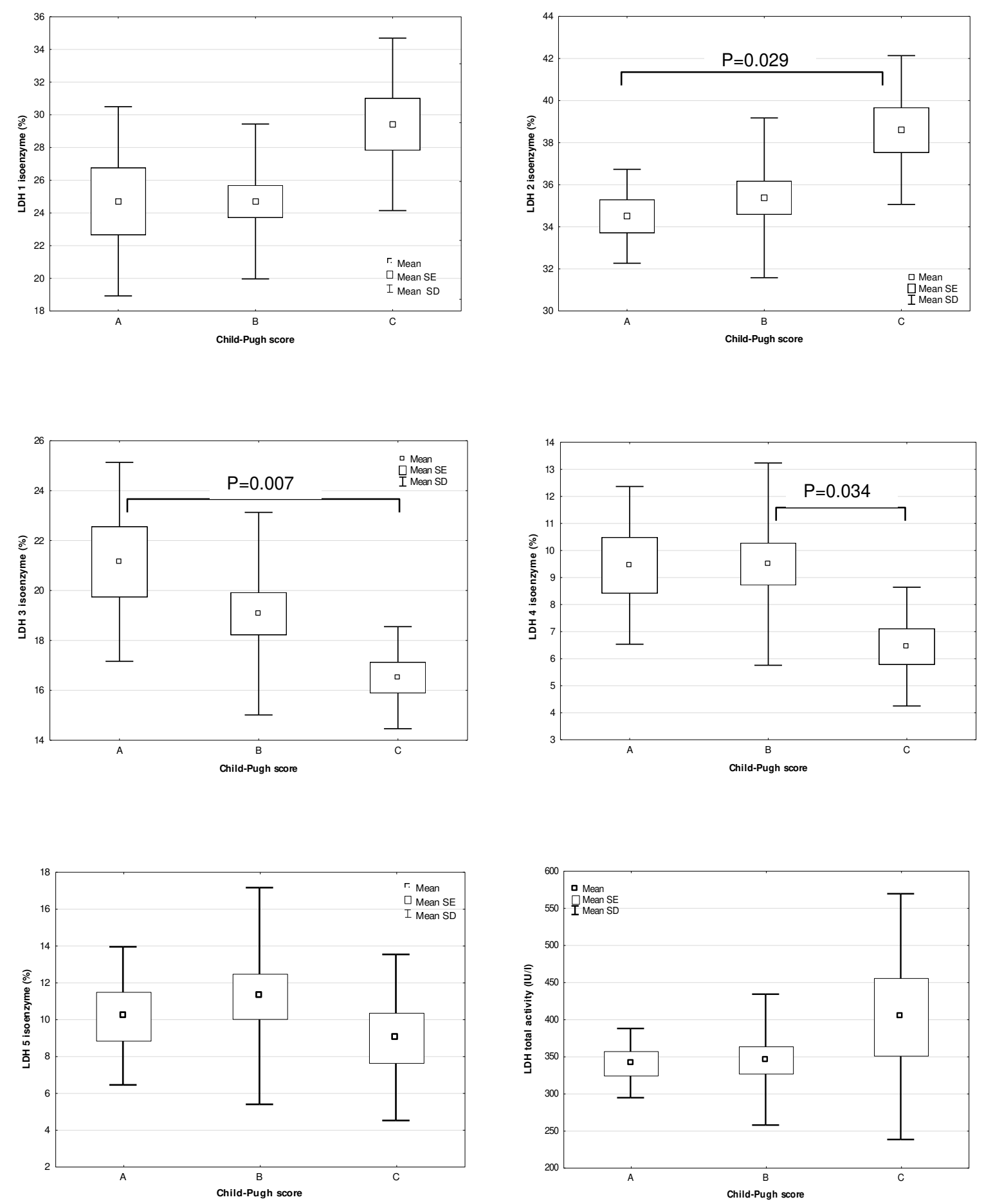

Fig. 3 The relative concentration of LDH isoenzymes in alcoholic cirrhosis according to the Child-Pugh score 

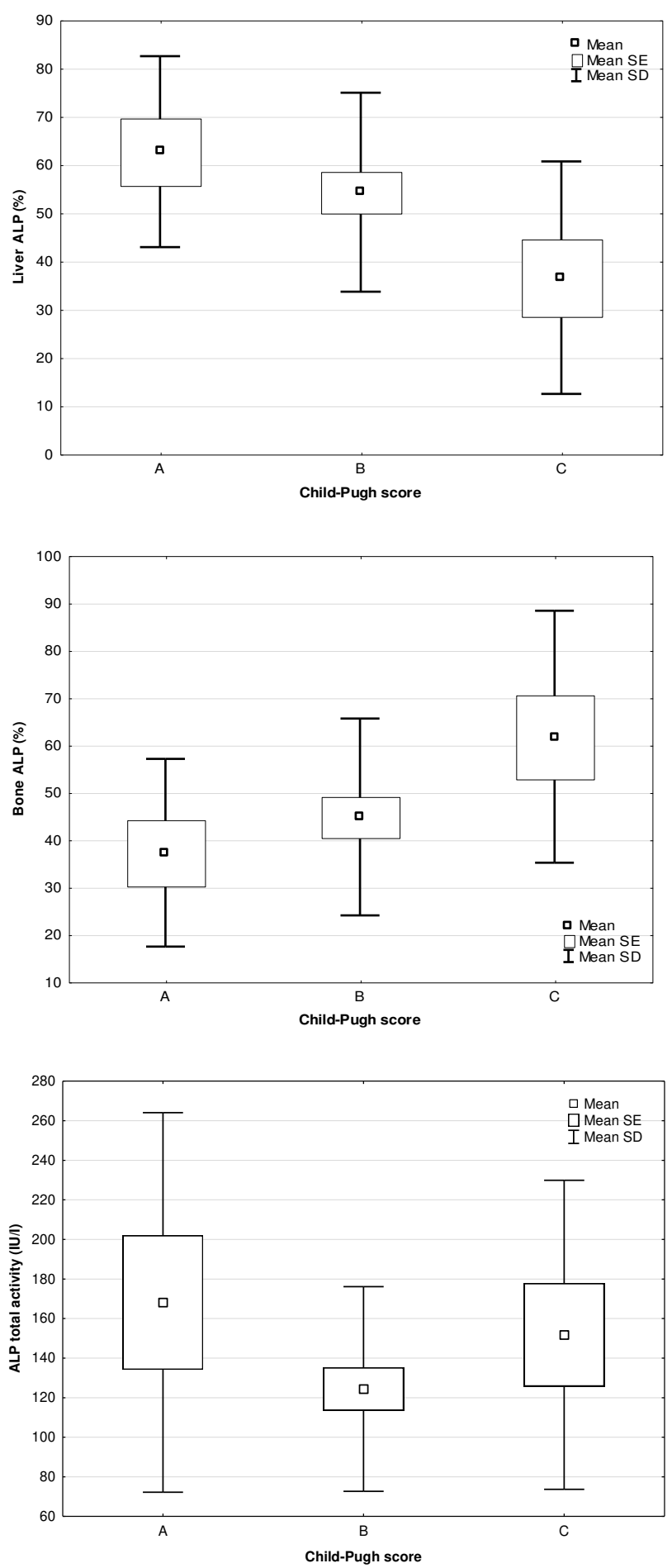

Fig. 4 The relative concentration of ALP isoenzymes in alcoholic cirrhosis according to the Child-Pugh score 
Figures
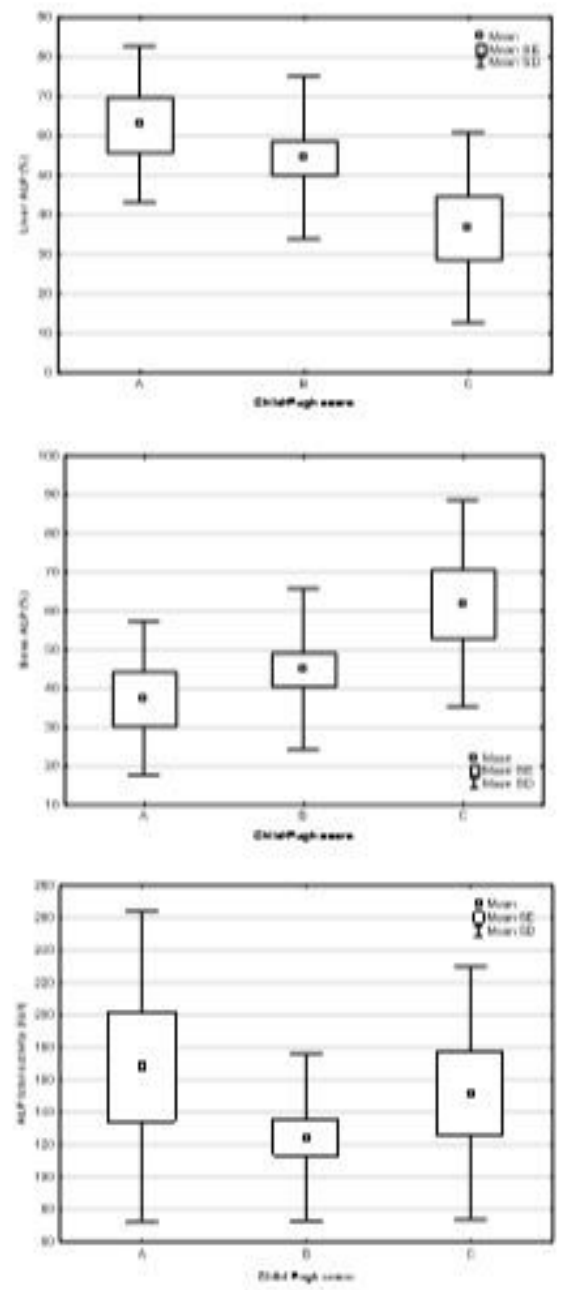

Figure 1

The relative concentration of ALP isoenzymes in alcoholic cirrhosis according to the Child-Pugh score 

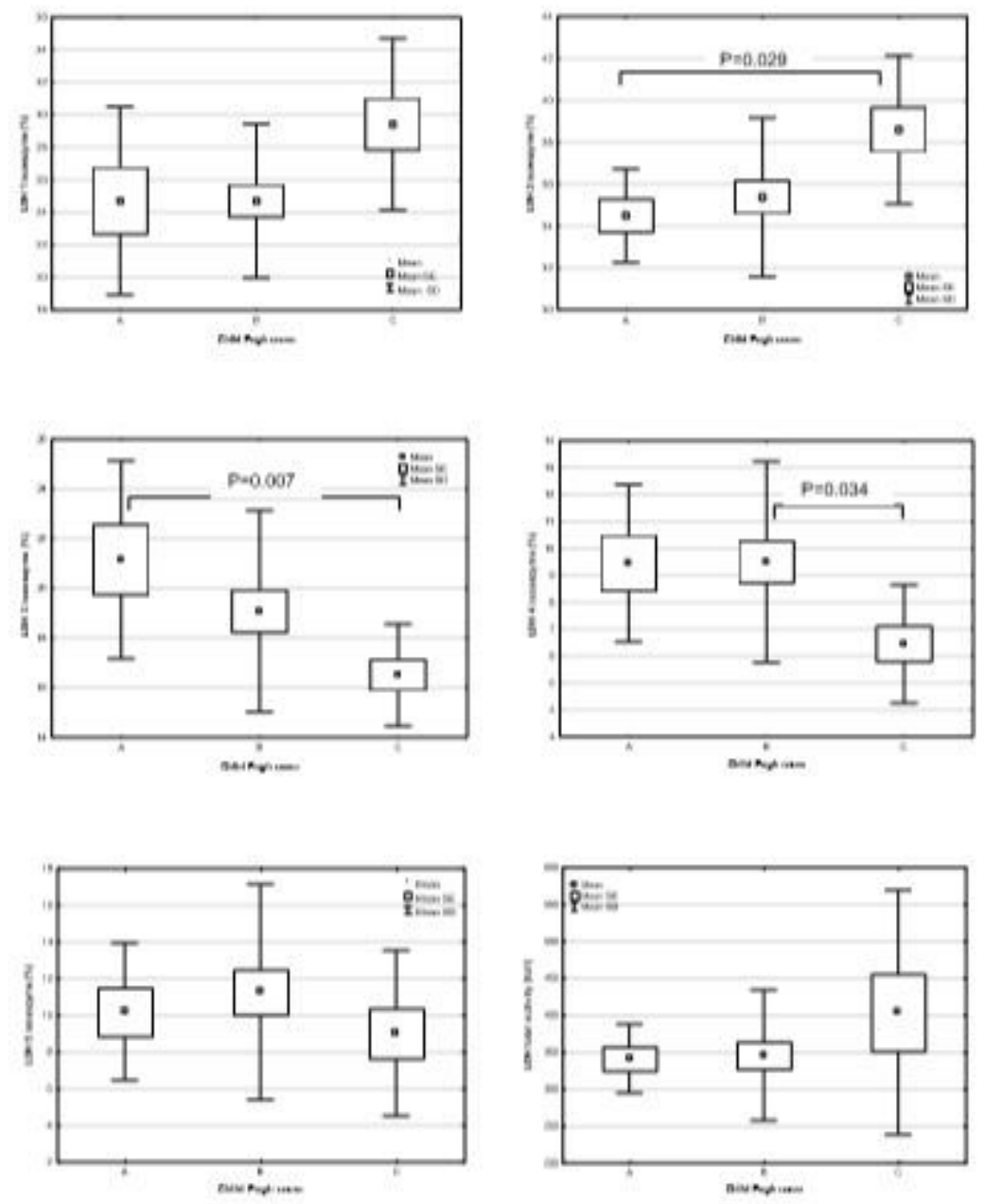

Figure 2

The relative concentration of LDH isoenzymes in alcoholic cirrhosis according to the Child-Pugh score

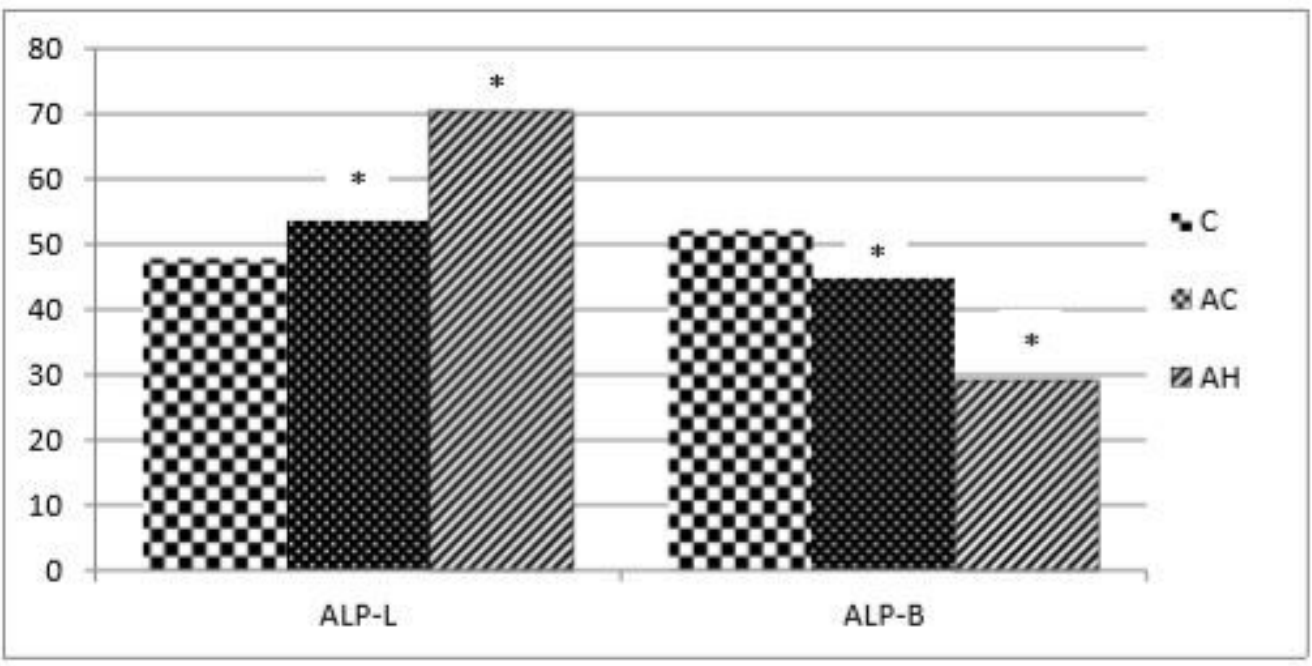

Figure 3 
The relative concentrations of ALP isoenzymes in alcoholic hepatitis (AH), alcoholic cirrhosis (AC) and in the control group (C)

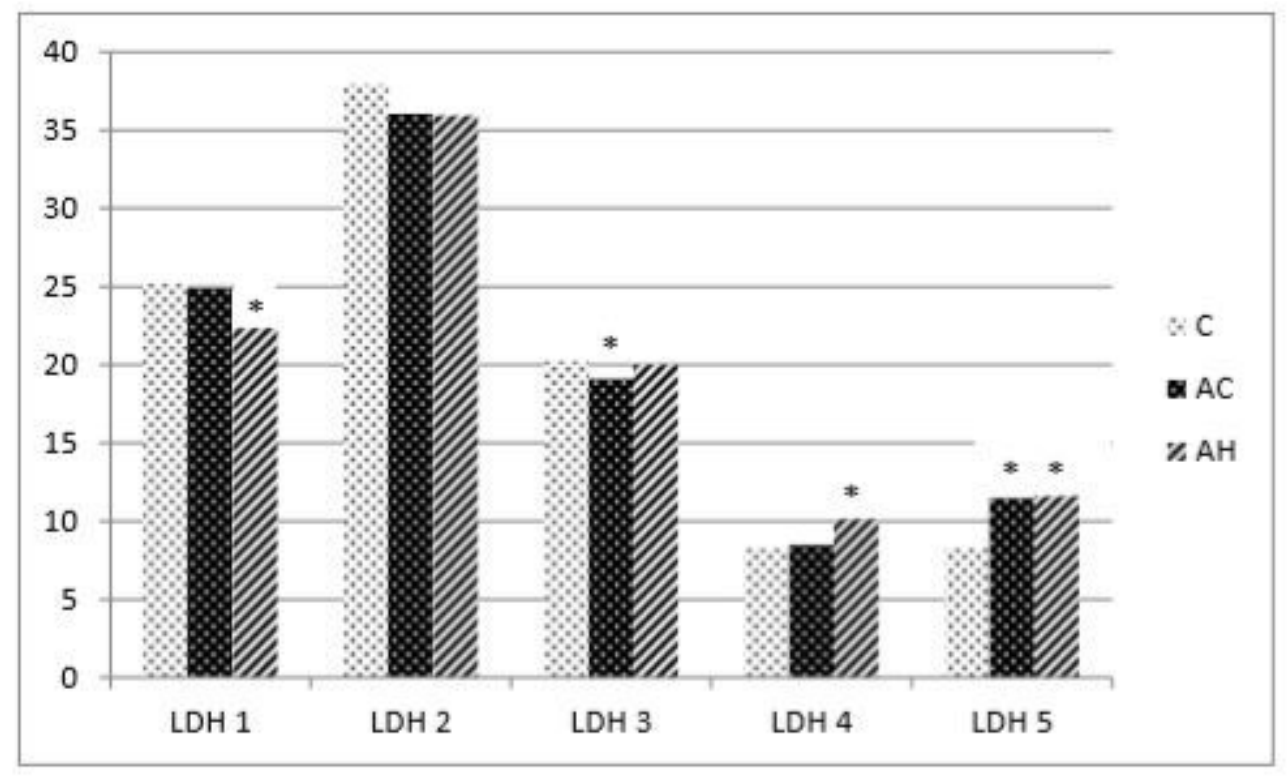

\section{Figure 4}

The relative concentrations of LDH isoenzymes in alcoholic hepatitis (AH), alcoholic cirrhosis (AC) and in the control group (C) 